\title{
Application of Neural Technology for Prediction Competitive Strategy of Trade Enterprises
}

\author{
Khamidullin R. Ya. ${ }^{1}$, Zyryanov S. I. ${ }^{2}$, Galushkin V. V. ${ }^{3}$, Kamalov N. B. ${ }^{4}$, Smirnova S. M. ${ }^{5}$ \\ ${ }^{1}$ Department of Higher mathematics and Natural Science, Synergy University, Moscow, Russia \\ ${ }^{2}$ Department of Higher mathematics and Natural Science, Synergy University, Moscow, Russia \\ ${ }^{3}$ Department of Higher mathematics and Natural Science, Synergy University, Moscow, Russia \\ ${ }^{4}$ Department of Higher mathematics and Natural Science, Synergy University, Moscow, Russia \\ ${ }^{5}$ Department of Higher mathematics and Natural Science, Synergy University, Moscow, Russia
}

\begin{abstract}
The article is devoted to the study of the specifics of forecasting the competitive strategy of retail enterprises based on the use of the method of neural networks. The main advantages and disadvantages of using this method are highlighted. The method of using neural networks to assess the financial condition of an enterprise is considered. An overview of methods for constructing neural networks for solving various types of economic problems and making decisions is made. The article describes the quality characteristics of neural networks of various types that have been constructed. A sequence of formation and implementation of competitive strategies has been developed, which makes it possible to choose a more rational strategy based on a comprehensive account of the factors of variability in the actions of competitive positioning of a trading enterprise. An analysis of the quality of the multi-level perceptron model is presented. A classification of new cases based on a neural network model is developed. The use of this model allows us not only to assess the financial condition of the enterprise, but also to predict the future and its level depending on the values of financial and non-financial indicators.

The main advantages of the proposed sequence is clearly pronounced multiplicity of actions on formation of the strategy; the presence of direct and reverse connections between the stages of the process that the VC eliminates not only strategic, but also analytical (information management), tactical (implementation strategy) and efficient (adjustment strategy) blocks that provide the quality of interaction of processes of strategy formation and its implementation.

To solve the problem of analytical support for forecasting the competitive strategy of retail enterprises in the short term, the necessity of using the method of neural networks, which is a component of the system of methods for evaluating and predicting the activities of retail enterprises, is justified. It is proposed to form a long-term competitive strategy of a trading
\end{abstract}

enterprise taking into account its cost, which is determined using a value chain model based on a balanced scorecard. This allows us to ensure an increase in revenue from sales of goods due to improved service, demand forecasting, compliance with contractual discipline, improving logistics, as well as increasing social responsibility of business, taking into account modern challenges of protecting the environment and introducing environmental Economics of the enterprise and social responsibility of business.

Key words :neural network, trading enterprise, forecasting, financial and non-financial indicators, economic processes.

\section{INTRODUCTION}

The development of promising areas of enterprise activity on the basis of mathematical modeling of the projected amount of income of a trading enterprise when assessing the impact of internal factors and exogenous risks is possible on the basis of non-Bank systems, which are subjective (expert) models of assessment and forecasting [1-3]. Today, artificial neural networks have become widespread for solving a large class of information processing problems - primarily for identification, simulation, intelligent control, and prediction of arbitrary time series under conditions of structural and parametric uncertainty [4]. Neural networks are promising computing technologies that provide new postulates for the study of control and analytical tools of activity in the activities of retail enterprises [5]. In a complex economic analysis using the method of applying neural networks, the current state of a trading enterprise is assessed, and in parallel, a causal analysis of changes in the main retail price under the influence of factors of influence is carried out [6-8]. At the same time, in the process of analyzing the financial and economic condition of a trading enterprise, taking into account the forecast for short and long $\square$ term periods, key indicators are justified, the value of which may lead to changes in the loan of a trading enterprise in a competitive environment [9]. Due to this, it is necessary to build a dynamic management tool - artificial neural networks, which can take into account the impact of 
management decisions on the profitability and cost of a commercial enterprise [10]. If necessary, the volume of input data of indicators can be increased, which will expand and clarify the information support of the control and analytical process of managing the activities of retail enterprises, not only for assessing the current state, but also for choosing a competitive strategy [11].

Quantitative and qualitative parameterization on the evidence-based analytical basis of strategy selection, the development of indicative plans and business planning, the formation of a long-term strategy of business partnership, and the assessment of performance with the strategy occurs within two processes. The first is the formulation process - a cognitive and decisive process aimed at defining the main strategic goals of the enterprise and identifying the main obstacles to their achievement. The second is the implementation process - the development of measures that will lead to the achievement of planned strategic goals [12]:

- economic indicators (high level of profitability and profitability, economic potential and effective sources of financing, availability of solvency);

- technical and technological (availability of advanced management system software, low level of depreciation of fixed assets and intangible assets, high level of information support due to the use of information technologies);

- organizational and managerial aspects (high level of corporate culture, effective organizational structure, degree of motivation of personnel, professional competence of management);

- marketing (presence of an effective strategy for promoting goods to the market, optimal pricing policy, a developed sales and representative network, a recognizable brand, a positive business image);

- socio-psychological (psychological attitude of consumers of goods, trust on the part of the population);

- geographical (geographical presence of a trading company in regions with developed market infrastructure and solvent consumer demand).

\section{MATERIALS AND METHODS}

The essence of the phenomenon most closely reflects the definition of cloud computing as a distributed data processing technology, in which computer resources and capacities are provided to the user as an Internet service.

Cloud computing is the result of combining many technologies and, above all, virtualization technologies (SOA, ASP, ASP.NET, web 2.0, grid, etc.) [10].

Currently, a set of mandatory characteristics of cloud computing has been formed, fixed at the level of the National Institute of statistics and technologies of the USA (NIST) [11]:

Self-service on-demand (On-demand self-service) - the consumer independently, as needed, provides the computing capabilities (server time, network storage, etc), requesting them from the service provider in unilateral automatic mode; universal network access (Broad network access) services are available over the network through standard mechanisms that support use by heterogeneous platforms thin and thick clients'; Resource pooling-a service provider combines resources to serve a large number of consumers into a single pool to dynamically redistribute capacity among consumers in the face of constant changes in capacity demand. Of particular importance is the independence from resource allocation, in which the customer, in General, does not know and does not control the exact physical location of the resources provided; high flexibility of services (Rapid elasticity). Computing capabilities are provided quickly and flexibly, in some cases automatically, to quickly increase scalability (scale out) and quickly release to reduce consumption (scale in); measured Service. Cloud systems automatically monitor and optimize resource usage by measuring it at a certain level of abstraction that corresponds to the type of service for the end user (for example, storage capacity, computing bandwidth, and active user accounts) [13-15].

There is also a well-established classification of service models within cloud services Software as a Service (SaaS); Platform as a Service (PaaS); Infrastructure as a Service (Iaas).

The SaaS model offers the end user the possibility to use remotely installed software: programs that are placed at the user's disposal, but function not so on their computers, but on the server side.

Services SaaS is particularly popular for small and medium-sized businesses and startups in a number of specific reasons: business requirements are fairly standard and do not require additional development costs and the use of non-standard software; controllability of the business is quite high due to its small size; this sector is usually not involved in long-term planning, takes higher risks to information assets and less demanding on information security.

The advantages of online software systems are traditionally attributed to the absence of full-scale costs for their acquisition and payment, which is carried out in proportion to the intensity of their use. At the same time, a significant part of the problems associated with the use of unlicensed software tools are being solved [3-7].

The PaaS model provides a set of services for using the cloud infrastructure to host both native software systems and standard software applications. A small share of PaaS services is due to the lack of an innovative component in the business models of domestic enterprises, most of which are engaged in the commodity industry or in services, Finance and trade.

The advantages of IaaS are the combination of extensive computing resources management capabilities (if this feature is required by the user) with savings in the cost of maintaining the physical and hardware infrastructure of the information and computing system [16].

The use of neural network-based methods for predicting enterprise performance has a number of advantages and disadvantages. The advantages are that the use of neural networks allows us to investigate the dependence of the predicted value on independent variables based on numerical and textual data, provided that there are unknown patterns; the analysis does not need to solve the problem of interdependence between input indicators; the stability to noise in the input data is determined; the analyst does not 
necessarily have knowledge of the high technological capabilities of neural networks [17]. This allows us to assume that sales in the future period will depend on the following parameters: sales in the last period; sales in the penultimate period; the number of business days, etc. However, you should also take into account uncontrolled environmental factors, in particular: seasonal nature, the activity of competitors in the area where the enterprise is located, the number of buyers, and the delivery period of the product.

The use of a neural network allows us to take into account factors that can be used to make short-term forecasts. Using a neural network architecture (a perceptron with a single hidden layer) and a database (retail turnover and other data from the external and internal environment), you can get an effective forecasting system. External parameters must be taken into account when enabling the appropriate input to the neural network. An algorithm is used to determine the importance and significance of input variables, with the exception of parameters that have little effect [18].

The advantage of neural networks is that the expert does not choose a mathematical model of time series behavior. The neural network model is built adaptively without the participation of an expert in the training process.

The disadvantage of this technique can be considered the need for specialized software tools; the complexity of meaningful interpretation of neural networks and non determinism. This refers to the so-called "black box", in which the decision-making logic of the neural network is hidden from the expert. Thus, the model does not allow us to clearly and transparently determine the contribution of each indicator to improving or worsening the financial condition of a merchant. For this purpose, there are algorithms for "extracting knowledge from a neural network", which formalize a list of logical rules, creating an expert system based on the network. However, these algorithms are not embedded in neural network packages, and the rule sets generated by such algorithms are quite large [21].

Consequently, to solve the problems of analytical support for forecasting the competitive strategy of retail enterprises, we propose to use the method of neural networks, which is a component of the proposed system of methods for evaluating and predicting the activities of retail enterprises.

Neurons United in a system of a certain architecture are called neural networks, the type of which is determined by the task that is assigned to the enterprise.

An important parameter for building a neural network is the optimization algorithm and the ability to learn. The optimization algorithm is extremely important for building a neural network, because it can correct errors in the process of forming a training set and speed up learning, so the algorithm for eliminating input components is chosen (those data that worsen the overall result are deleted) [19].

The work of the neural network estimate based on the restock of relatively simple elements of the same type, where each of the neurons contain synapses (unidirectional inputs $x_{1}, \ldots x_{n}$ that are associated with other hidden neurons) and an axon (output values $y_{1}, \ldots y_{m}$, associated with the hidden and input neurons) [20].

In the process of preparing for forecasting, the entire data set is divided into three subsamples. The first is training, during which a set of examples is selected for the effective functioning of networks, each of which contains a pair of data: input $x_{i}$ and $y_{j}$. To train the perceptron, we use data from a set of observations $x_{i}$. In this case, each neuron of the hidden layer receives signals from neurons of the input layer. After performing operations on the signals, the weights of the neuron change, which transmits its output to the cex of the next layers of neurons, providing a feed forward transmission to the output $y_{j}$, thereby providing efferent connections [22].

The second is considered as a validation, because it is designed to provide the possibility of evaluating the forecast and determining the optimal complexity of the model. The last bid is used to evaluate the effectiveness and realism of the proposed model. It tests the network after training [23].

Figure 1. shows a four-layer network, the first node of which contains four neurons, the second - three, the third - two, and the fourth - three neurons.

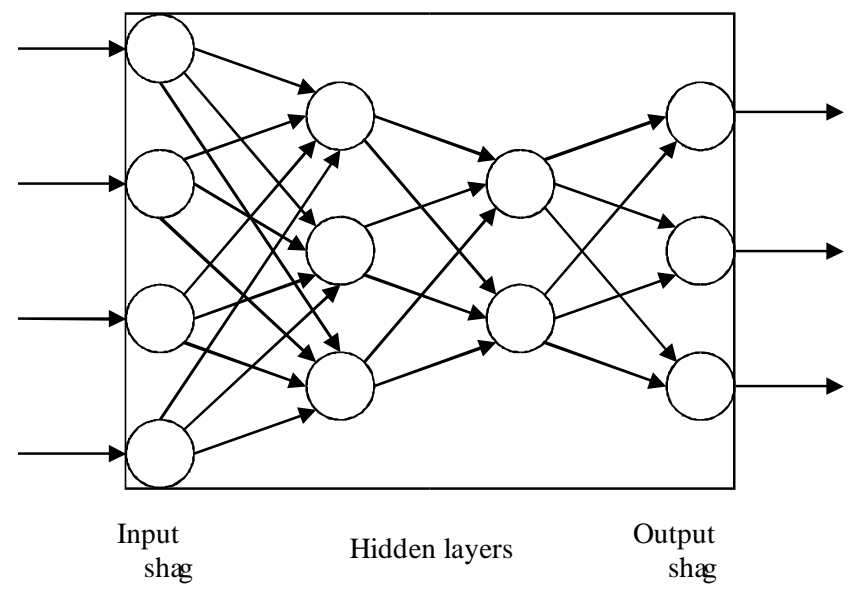

Figure 1: Structure of a four-layer neural network

The development and use of neural networks with the full use of NeuralTools includes four stages (figure 1).

Step 1. the Data that is used in NeuralTools is defined in the data sets to be prepared. Data Set Manager allows you to set data sets so that they can be repeatedly applied when designing networks. Before the simulation of neural networks were introduced in the input data. This step allowed us to get rid of a significant range of data and get ranges of variables. The option was chosen when the standardization of indicators is carried out on the basis of variational scope [25].

Stage 2. During training, a neural network is created based on a lot of data. After all, the neural network configuration is loaded from the database during forecasting. The forecast results are presented to the user as an HTML report. After training is complete, the network configuration is saved to the database. When the app is running, a database is used to store information [26].

As a scientists notes, "the most important decision that an analyst should make when working with neural networks is the choice of a set of variables to describe the modeled process of analyzing the company's financial and economic activities" [1]. Accordingly, the data is compiled on the basis of SPO, for which the values of both dependent and independent variables are known. 
According to the study factors of the first level connections are the net income, cost of goods sold, distribution costs; the level of derivative - trading margin, switch customer service; in turn, factors of the second level are sales prices, product range and sales organization, a separate rhythm, and use of resources.

Stage 3. During testing of the neural network, we tested the possibility of predicting the initial values. The data that was used for testing were certain sets of historical data.

The main strategic indicator that is calculated during forecasting should be the basis of the strategy. Therefore, we have propose joint venture with the ratio of the company's market value to the value of its assets as the main strategic parameter. The indicator of the enterprise value in absolute terms can be used to characterize the enterprise according to the criterion of its financial stability. Among other strategic indicators, we have highlighted profitability, the amount of gross profit, the amount of current assets and inventory.

Step 4. Developed a neural network used to predict unknown input values. The neural tools DOS tool allows you to set parameters for automatically searching for the best network with appropriate strategic indicators.

According to the research, net profit tends to grow by about $20 \%$ annually and is the result of effective management of a trading enterprise, provided that it retains its competitive advantages and market positions. The assessment of the amount of current assets and inventories indicates an increase in the amount of accounts receivable and cash, which is evidence of balancing the enterprise at the level of growth strategy. The question of the correct and clear choice of strategy is quite important, because choosing a strategy in the short term and its compliance in the long term depends on the economic and political environment, as well as the legal support for the activities of enterprises of various forms of organization.

Therefore, based on the data we proposed the company use a corporate strategy of sustainable balanced growth on the basis of "key success factors", which provides for the protection of market based on the optimization of capital structure; policies of cash flow management and financial risk management policy organizational structure, modification of the product (private label); maintaining a balance between quality of services and the quality of communications; the implementation of the price leadership (cost leadership), optimization of financial flows, valuation and transfer of certain business processes outsourcing.

The main advantages of this method is the increase in income from sales of goods by improving the level of service, accurate supply and demand forecasting; observance of contractual discipline; the reduction of cost by reducing inventory level, minimizing overhead and transaction costs in procurement, warehousing and distribution, as well as use of logistical capacities; the achievement of customer-oriented business processes, their openness to knowledge sharing between business partners; increase the social responsibility of business, given the current challenges of environmental protection.

\section{CONCLUSION}

For a long-term competitive strategy of trade enterprises, we offer you to use the model of value chain costs for the company, which should take into account the increase in income from sales of goods by improving the level of service uniformity of procurement of goods and demand forecasting; observance of contractual discipline; reduction of costs by reducing the level of smell, and owls, as well as overhead and transaction costs in procurement, warehousing and distribution and improving the utilization of logistics capacity; achievement of customer-oriented business processes, their openness to knowledge sharing between business partners.

\section{REFERENCES}

1. Châlons C, Dufft N (2016) Die Rolle der IT als Enabler für Digitalisierung. In: Abolhassan F (ed) Was treibt die Digitalisierung? Warum an der Cloud kein Weg vorbeiführt. Springer, Wiesbaden, pp 27-37

2. Yanosky R (2008) From users to choosers: the cloud and the changing shape of Enterprise Authority. In: Katz RN (ed) The tower and the cloud. Educause E-book, campanile. University of California, Berkeley, pp 126-136

3. Armbrust M, Fox A, Griffith R et al (2010) A view of cloud computing. Commun ACM 53:50-58. https://doi.org/10.1145/1721654.1721672

4. Ragowsky A, Licker P, Miller J et al (2014) Do not call me chief information officer, but chief integration officer. A summary of the 2011 Detroit CIO roundtable. Commun Assoc Inf Syst 34:1333-1346

5. Wang N, Liang H, Jia Y et al (2016) Cloud computing research in the IS discipline: a citation/co-citation analysis. Decis Support Syst 86:35-47.

6. Cooper J, Bradley DB (2014) Cloud Computing's selection and effect on small business. Entrep Exec 19:87-95

7. Schneider S, Sunyaev A (2016) Determinant factors of cloud-sourcing decisions: reflecting on the IT outsourcing literature in the era of cloud computing. J Inf Technol 31, 31(1). https://doi.org/10.1057/jit.2014.25

8. Chang V, Walters RJ, Wills G (2015) Delivery and adoption of cloud computing Services in Contemporary Organizations. IGI Global

9. Kappelman L, McLean E, Johnson V et al (2017) The 2016 SIM IT trends study. MIS Q Exec 16:55-83

10. Heidkamp P, Pols A (2016) Cloud-monitor 2016: cloud-computing in Deutschland - status quo und Perspektiven. KPMG AG

11. Zacher M (2017) Cloud Computing in Deutschland 2017. IDC Central Europe GmbH, Frankfurt

12. Tang C, Liu J (2015) Selecting a trusted cloud service provider for your SaaS program. Computers and Security 50:60-73. https://doi.org/10.1016/j.cose.2015.02.001

13. Trenz M, Huntgeburth J, Veit D (2017) How to Succeed with Cloud Services? Business \& Information Systems Engineering OnlineFirst Article. 
https://doi.org/10.1007/s12599-017-0494-0

14. Labes S, Hanner N, Zarnekow R (2017) Successful business model types of cloud providers. Business \& Information Systems Engineering 59:223-233. https://doi.org/10.1007/s12599-016-0455-z

15. Döring N, Bortz J (2016) Forschungsmethoden und Evaluation in den Sozial- und Humanwissenschaften. Springer Gabler 1051. https://doi.org/10.1007/978-3-642-41089-5

16. Schneider S, Sunyaev A (2015)

Gestaltungsempfehlungen für Cloud-Service-Zertifizierungen. In: Cloud-Service-Zertifizierung. Springer, Berlin, pp 63-68

17. Bartels A (2016) US tech market outlook for 2016 and 2017: cloud and business caution will slow growth. In: Forrester research, Cambridge

18. Riegel L, Schick M (2016) The German internet industry 2016-2019. Arthur D, Little GmbH, Frankfurt

19. Abramov, R. A., \& Sokolov, M. S. (2017). Features of corruption in the educational sphere in the context of globalization of educational space. Journal of Legal, Ethical and Regulatory Issues, 20(Special issue 1).

20. Semenyutina, A. V., Khuzhakhmetova, A. S., Lazarev, S. E., Semenyutina, V. A., \& Sapronova, D. V. (2019). Scientific basis for the formation of multifunctional cluster dendrological expositions of collections of the Federal Research Center for Agroecology of the Russian Academy of Sciences. World Ecology Journal, 9(2), 39-63. https://doi.org/10.25726/worldjournals.pro/WEJ.2019.2.3

21. Semenyutina, A. V., \& Lazarev, S. E. (2019). Diagnostic characteristics of representatives of the genus robinia l. by generative indicators in introduction populations. World Ecology Journal, 9(2), 64-94. https://doi.org/10.25726/worldjournals.pro/WEJ.2019.2.4

22. Shashkova, A. (2019). Regulating principles of disclosure of information to shareholders under G20 / OECD principles. In Proceedings of the $33 \mathrm{rd}$ International Business Information Management Association Conference, IBIMA 2019: Education Excellence and Innovation Management through Vision 2020 (pp. 1931-1936).

23. Gennadievich, B. A. (2020). Machine learning and data mining activity results when using projectiles in different sports. International Journal of Advanced Trends in Computer Science and Engineering, 9(3), 3157-3160. https://doi.org/10.30534/ijatcse/2020/103932020

24. Burov A.G., Agüero D. Implementation of the Principles of Innovative Entrepreneurship in the Field. Academy of Entrepreneurship Journal. 2019. Vol. 25. Issue 1S. pp. 1-5.

25. Ristanto, R. H., Miarsyah, M., Muharomah, D. R., Astuti, T. A., Aini, S., \& Prihatin, A. I. (2020). Light-board: Simple media to learn photosynthesis concepts. International Journal of Advanced Trends in Computer Science and Engineering, 9(1), 299-303. https://doi.org/10.30534/ijatcse/2020/45912020

26. Rivai, M. A., \& Wang, G. (2020). Cloud computing platform services in the university libraries for digital repository. International Journal of Advanced Trends in Computer Science and Engineering, 9(1), 285-294. https://doi.org/10.30534/ijatcse/2020/43912020 